\title{
Christenson, S. and Reschly, A. (Eds.) (2010). Handbook of School-Family Partnership. New York: Routledge, Taylor and Francis. 544 p., ISBN 10: 0-415- 96376 / ISBN 13: 978-0-415-96376-3.
}

Reviewed by John W. EAGLE ${ }^{1}$ And SHANnON Dowd-EagLE ${ }^{2}$

Sandra Christenson, Dr., received her Ph.D. in Educational Psychology (School Psychology) from the University of Minnesota in 1988. She is a prolific author, having contributed to over 100 articles or book chapters and five books on topics including school-family partnerships and student engagement. Noteworthy accomplishments include the prestigious 1992 Lightner Witmer award from the American Psychological Association for early career accomplishments, the 2005 Blanche F. Ittleson Award for her research related to school-family partnerships, and the 2007 recipient of the Senior Scientist Award from APA Division 16 in recognition for career-long contributions and scholarship to the field of School Psychology.

Amy Reschly, Dr., is an Associate Professor at the University of Georgia and received her Ph.D. in Educational Psychology (School Psychology) from the University of Minnesota in 2004. She has authored or co-authored over 35 publications, serves as an Associate Editor of School Psychology Quarterly and is a member of the editorial board for the Journal in School Psychology and the Journal of Early Intervention.

The assertion that school and family contexts play an integral role in the academic, behavioural, and social-emotional development of children is unquestionable. Although research efforts have often explored the respective contributions of these primary systems, recent attention has emphasised the reciprocal influences between home and school contexts as a means to promote learning and to enhance student outcomes. Grounded in ecological systems theory (Bronfenbrenner, 1992), empirical work has identified numerous benefits associated with the formation of school-family partnerships including improved student performance, increased positive attitudes regarding school, better school attendance, fewer behavioural problems and better study and

1 Rhode Island College

2 Rhode Island College 
homework habits (Christenson \& Sheridan, 2001). The implications of these findings have informed policy decisions and served as driving forces behind educational reform efforts, reflected in several national initiatives including the Individuals with Disabilities Education Act (1997) and National Education Goals in the United States.

The Handbook of School-Family Partnerships provides a comprehensive review of theory, research and practice as it relates to meaningful collaboration between families and schools. It is divided into three sections: (I) the theoretical and empirical underpinnings of partnerships, (II) partnership considerations across developmental levels, and (III) the establishment of a research agenda to inform policy and practice. The editors provided a synthesis of themes that were evident in all chapters included in the text:

- It is critical to understand and appreciate the role culture plays in the development of positive home-school partnerships.

- Numerous evidence-based home-school interventions exist that promote the academic, behavioural and social-emotional competence of students across developmental levels.

- $\quad$ Effective home-school relationships are predicated upon the belief that families are part of the solution in enhancing student outcomes. They are not the problem.

- The development of constructive partnerships across the primary systems in a child's life is necessary to minimise educational disparities.

- The conditions that support effective cross-setting connections are clear and grounded in research.

- $\quad$ Additional research, particularly related to the terminology, measurement, design and the generalisation of effective practices, is needed.

- It is time to promote a comprehensive, systematic and continuous approach for home-school partnerships.

Section I of the book consists of five chapters, which outline the theoretical and empirical bases of school-family partnerships. The selected authors are experts in the field and provide a high level of professional discourse and vision. They begin with a presentation of the developmental/ecological model as a conceptual framework for current and future research, programs, and public policies related to family-school partnerships and child outcomes. Authors Jason Downer and Sonya Myers clearly demonstrate how both ecological systems and developmental theories are applied when considering the complexities and multiple characteristics of family-school partnerships. Drawing from Bronfenbrenner's (1986) ecological systems theory and Pianta and Walsh's (1996) developmental 
adaptation, the authors highlight the importance of understanding the patterns of interactions among key systems in a child's life over time. Based on this theoretical orientation, child development occurs in the context of multiple environmental systems that are interrelated including the microsystem, mesosystem, exosytem, macrosystem and chronosystem. The mesosytem, comprised of relationships between primary microsystems, is considered the theoretical cornerstone for home-school partnerships and provides a basis for understanding the reciprocal and ever-changing influences on a child's social, behavioural, and academic success. Chapters 2 and 3 extend the discussion by exploring conditions that facilitate the formation of productive mesosystemic relationships. These contributions provide theoretical and empirical insights into questions such as "what" motivates families and educational professionals to partner and "what" elements are necessary to develop healthy relationships. The authors also examine underlying belief systems, commitment to partnering and the importance of congruence across home and school contexts. Section I concludes with a discussion of culture, the importance of diversity in families and its role in a child's development and learning. Lynn Okagaki and Gary Bingham present empirical research that attempts to evaluate cultural models related to their involvement in their child's education. Cultural and economic diversity are portrayed in relation to parental aspirations and expectations for their child. Nancy Hill extends the multicultural conversation by presenting how culturally-based world views can impact family-school interactions. The author focuses on how cultural and familial beliefs, values, and practices, across ethic groups affect family engagement in educational settings. Perspectives from African-American, Asian-American, and Latino families are highlighted.

Section II presents nine chapters from researchers who provide empirical evidence supporting the role of cross-setting partnerships in promoting children's competence across developmental levels. This developmental perspective adds to the comprehensiveness of the text that covers areas of academic achievement, social-emotional skills, communication skills, and school connectedness. A common theme in this section relates to the challenges and opportunities for enhancing family-school partnerships in educational settings.

The initial focus of this section relates to the importance of family engagement for student academic achievement. Specific aspects of family-school partnerships explored by authors include: (a) the type of parent-child activities, parent-child relationships, and parenting styles that are associated with a child's academic achievement; (b) enhanced student outcomes, long-term results, and greater academic gains; and (c) the specific impact on reading and mathematics achievement. Other authors concentrated on research-based interventions that 
include substantial family engagement, specifically Carolyn Webster-Stratton and M. Jamila Reid discuss the Incredible Years (IY) program and Elizabeth Stormshak, Thomas Dishion, and Corrina Falkenstein present the ECOFit model. Researchers of both programs provide empirical support for the models and how to incorporate these intervention programs in schools. Finally, a discourse surrounding the importance of school-family partnerships for both interventions with young children and the development of such partnerships during adolescent years is provided.

The seven chapters in Section III bring together expert commentary and research to provide a framework for future policy and practice change. The section begins by challenging the notion of the "hard-to-reach" parent and suggests that it is the educational institution, not the families, that are "hard-to-reach." The adoption of a strength-based approach that re-conceptualises families as part of the solution, rather than the problem, is at the heart of family-school partnership research. Throughout this section, several authors provide empirical support for the formation of constructive home-school relationships including increases in parents' reported feelings of self efficacy, improved family well-being, enhanced child functioning and competence, deeper understanding related to the roles all parties play in child development, and improved student achievement. Although a strong empirical base exists, the need for additional research was a consistent theme identified by contributors to the Handbook. Several authors outlined conceptual and methodological concerns including issues related to terminology, measurement, design and generalisation of practices. In response to the need for more sophisticated measurement, structural equation modelling was offered as a promising approach for future research. The implications of research advancements on policy and practice are also discussed in this section. Authors Heather Weiss and Naomi Stephen highlight that current thinking about educational reform has adopted a broader view, emphasising the role of family, school and community partnerships in minimising educational disparities. They contend that the next step is to move beyond "random acts of parent involvement" (Gil Kressley, 2008) to promote a comprehensive, systematic and continuous approach for home-school partnerships.

In conclusion, the editors of this comprehensive volume have put together an array of state-of-the-art research and discourse related to family-school partnerships. They have provided a text that effectively balances research and practice. It is an essential body of reading for educators and researchers alike. The theoretical and empirical support for family-school partnerships is clearly outlined, as is a framework for how to maintain and enhance these partnerships in the future. The editors and authors have created an exceptional work that presents 
technical, empirical data in a format that is easily digestible for practitioners. It is an essential component to any school, district, or academic institutions that is interested in developing more effective school-home partnerships.

\section{References}

Bronfenbrenner, U. (1986). Ecology of the family as a context for hum development: Research perspectives. Developmental Psychology, 22, 723-742.

Bronfenbrenner, U. (1992). Ecological systems theory. In R. Vasta (Ed.), Annals of child development. Six theories of child development: Revised formulations and current issues (pp. 187-249). London: Jessica Kingsley.

Christenson, S. L., \& Sheridan, S. M. (2001). Schools and families: Creating essential connections for children's learning. New York: Guilford.

Gil Kressley, K. (2008, August). Breaking new ground: Seeding proven practices into proven programs. Session description from the National PIRC Conference, Baltimore, MD.

Pianta, R. C., \& Walsh, D. J. (1996). High-risk children in schools: Constructing sustaining relationships. New York: Routledge. 